\title{
Fabrication of Dense Gadolinia-Doped Ceria Coatings via Very-Low-Pressure Plasma Spray and Plasma Spray-Physical Vapor Deposition Process
}

\author{
Jing Wen ${ }^{1,2,+}$, Chen Song ${ }^{2,3,+}, *$, Taikai Liu ${ }^{2}$, Ziqian Deng ${ }^{2}$, Shaopeng Niu ${ }^{2}$, Yapeng Zhang ${ }^{2}$, \\ Libin Liu ${ }^{1}$ and Min Liu ${ }^{2}$ \\ 1 School of Materials Science and Engineering, Central South University, Changsha 410083, China; \\ 173114197@csu.edu.cn (J.W.); lbliu@csu.edu.cn (L.L.) \\ 2 Guangdong Institute of New Materials, National Engineering Laboratory for Modern Materials Surface \\ Engineering Technology, the Key Lab of Guangdong for Modern Surface Engineering Technology, \\ Guangzhou 510651, China; liutaikai@gdinm.com (T.L.); dengziqian@gdinm.com (Z.D.); \\ niushaopeng@gdinm.com (S.N.); zhangyapeng@gdinm.com (Y.Z.); liumin@gdas.gd.cn (M.L.) \\ 3 School of Environment and Energy, South China University of Technology, Guangzhou 510006, China \\ * Correspondence: songchen@gdinm.com \\ + Co-first author.
}

Received: 18 September 2019; Accepted: 25 October 2019; Published: 1 November 2019

\begin{abstract}
Gadolinia-doped ceria (GDC) is a promising electrolyte material for low-temperature solid oxide fuel cells (LT-SOFCs). Many works used ceramic sintering methods to prepare the GDC electrolyte, which was mature and reliable but presented difficulties in rapidly preparing a large area of GDC electrolyte without cracks. The low-pressure plasma spray (LPPS) process has the potential to solve this problem, but few studies have been conducted to date. In this work, submicron GDC powder was agglomerated by a spray drying method to achieve the proper granularity with $D_{50}$ about $10 \mu \mathrm{m}$, and then two dense GDC coatings were fabricated with this agglomerated GDC powder using very-low-pressure plasma spray (VLPPS) and plasma spray-physical vapor deposition (PS-PVD), respectively. The results indicate that the two GDC coatings exhibited similar microstructure but with different densification mechanisms. The VLPPS coating was mainly built up in the form of liquid splats, which had lower mechanical properties due to the lower density and crystallinity, while the PS-PVD coating was co-deposited with the vapor clusters and liquid splats, which had higher density, crystallinity, and mechanical properties. It can therefore be concluded that the GDC coating prepared by PS-PVD is more appropriate for the LT-SOFC application.
\end{abstract}

Keywords: gadolinia-doped ceria coatings; very-low-pressure plasma spray; plasma spray-physical vapor deposition

\section{Introduction}

The solid oxide fuel cell (SOFC) is a new type of green power generation device that can directly convert the chemical energy of fuels into electric energy at high efficiency [1]. A current research hotspot is to develop SOFCs capable of operating at low temperature $\left(\leq 600{ }^{\circ} \mathrm{C}\right)$, aiming to reduce the cost and extend the battery life [2]. However, lowering the operating temperature will increase the electrolyte resistance leading to a significant decrease in battery performance. A proposed solution is to develop a dense electrolyte coating with high electrical conductivity at low temperatures. Gadolinia-doped ceria (GDC) is one of the most promising candidates, as its ion conductivity at $600{ }^{\circ} \mathrm{C}$ reaches $0.01-0.02 \mathrm{~S} / \mathrm{cm}$ [3]. The conventional preparation method for the GDC electrolyte is sintering, but this makes it difficult to rapidly prepare dense GDC electrolyte on a large area without cracks. 
As an alternative method, the low-pressure plasma spray (LPPS) process is promising, with significant advantages, as the high-power plasma jet at low pressure can completely melt the electrolyte material and accelerate it to $2-3$ times the speed of sound, which is beneficial to increase the density of the coating. In addition, the deposition efficiency is much higher than traditional vapor deposition processes, enabling rapid and uniform preparation on a large area [4-10]. By adopting different plasma torches and powers, the LPPS can be divided into the very-low-pressure plasma spray (VLPPS) and plasma spray-physical vapor deposition (PS-PVD). The difference between them is that the VLPPS coating is mainly deposited with the melted particles, and the PS-PVD coating can be made with the mixed vapor and liquid phases or pure vapor phase. Marcano [11] used PS-PVD to prepare a dense 8YSZ (yttria-stabilized zirconia) electrolyte. The open-circuit voltage and power density of the single cell were $1.033 \mathrm{~V}$ and $0.89 \mathrm{~W} / \mathrm{cm}^{2}$ at $800{ }^{\circ} \mathrm{C}$, respectively. Gao [5] used VLPPS technology to prepare a dense scandia-stabilized zirconia electrolyte (ScSZ). The gas leakage rate was only $1.4 \times 10^{-7} \mathrm{~cm}^{4} \mathrm{gf}^{-1} \mathrm{~s}^{-1}$, and the maximum power density of single cells could reach $0.402 \mathrm{~W} / \mathrm{cm}^{2}$ and $1.164 \mathrm{~W} / \mathrm{cm}^{2}$ at $650{ }^{\circ} \mathrm{C}$ and $750{ }^{\circ} \mathrm{C}$, respectively. These studies demonstrated that the electrolytes prepared by the LPPS process are able to meet the operating requirement of SOFCs. However, most researchers used LPPS to prepare medium-high temperature SOFC electrolytes, such as YSZ and ScSZ coatings. Few studies have focused on the preparation of GDC electrolytes for low-temperature solid oxide fuel cells (LT-SOFCs) via LPPS.

In this paper, a specially formulated agglomerated GDC powder, suitable for LPPS, was prepared via a spray drying process. Then the VLPPS and PS-PVD processes were used to prepare the dense GDC coatings. The adoption of different plasma torches, gases, and powers resulted in that GDC coatings exhibited similar dense microstructures. In order to explain this phenomenon, the morphologies and compositions of the two GDC coatings were analyzed. Additionally, the mechanical properties of coatings were measured, as they are essential for the SOFC application, especially for the electrolyte-supported SOFCs [12]. Finally, a deposition mechanism model was built to demonstrate the formation processes of the dense GDC coatings using VLPPS and PS-PVD.

\section{Experimental Procedure}

Since the submicron powder was too hard to be radially delivered into the low-pressure plasma jet, $\mathrm{Ce}_{0.8} \mathrm{Gd}_{0.2} \mathrm{O}_{1.9}$ powder with an average size of $150 \mathrm{~nm}$ was self-agglomerated by a spray dryer (MOBILE MINOR, GEA Niro). The suspension preparation process for the spray drying was as follows: Firstly, the GDC powder, deionized water, and dispersant of polyacrylic acid (PAA, DAMAO CHEMICAL REAGENT) were mixed and milled with agate balls for $2 \mathrm{~h}$. After thorough mixing and milling, another binder of polyvinyl pyrrolidone (PVP, DAMAO CHEMICAL REAGENT) was added and continually milled for another $15 \mathrm{~h}$. The resultant GDC suspension was then transformed with a peristaltic pump into a co-current two-fluid nozzle, where it was atomized by compressed air. Finally, the hot air entered the chamber through a ceiling air disperser, evaporated the solution, which resulted in a dried agglomerated GDC powder. The spray drying parameters are listed in Table 1. For spraying the GDC coating, the vacuum plasma spraying system (ChamPro, Oerlikon Metco) was employed, which was equipped with the F4-VB and O3CP plasma torches. Carbon steel plates were used as the substrates due to their suitable thermal expansion coefficient. Before spraying, all the substrates were sandblasted and preheated to $600{ }^{\circ} \mathrm{C}$ using the plasma jet. The substrate temperature was recorded by an infrared thermometer. The other detailed spraying parameters are shown in Table 2. The VLPPS parameters favored the melting of GDC powder, and the PS-PVD parameters favored its vaporization. We chose these two parameters to obtain GDC coatings deposited in different states, so as to explore which deposition mode is more conducive to the densification of GDC coatings.

For characterization, the particle size of the spray-dried agglomerated powder was measured by a laser particle size analyzer (MASTERSIZER 3000, Malvern, UK). The phase compositions of the powder and coatings are studied using an X-ray diffractometer ( $\mathrm{Cu} K \alpha$ radiation; Rigaku, Tokyo, Japan) operating at $40 \mathrm{kV}$ and $100 \mathrm{~mA}$. The coating microstructures and porosities were observed by 
field-emission scanning electron microscopy (FEI, Hillsboro, OR, USA) and ImageJ software, respectively. The cross-sectional nanoindentations were measured using a nanoindenter (NHT2, Anton-Paar, Graz, Austria) with a diamond Berkovich tip at a maximum load of $10 \mathrm{mN}$. The loading and unloading rate, holding time, and temperature were $20 \mathrm{mN} / \mathrm{min}, 10 \mathrm{~s}$, and $25^{\circ} \mathrm{C}$, respectively. The microhardness and elastic modulus were calculated using the Oliver-Pharr method [13].

Table 1. Spray drying parameters. GDC: gadolinia-doped ceria.

\begin{tabular}{cc}
\hline Parameters & Value \\
\hline GDC powder content $(\mathrm{wt} . \%)$ & 56 \\
Dispersant content $(\mathrm{wt} . \%)$ & 3 \\
Binder content $(\mathrm{wt} . \%)$ & 4.5 \\
Suspension feeding rate $(\mathrm{mL} / \mathrm{min})$ & 70 \\
Air inlet temperature $\left({ }^{\circ} \mathrm{C}\right)$ & 240 \\
Air outlet temperature $\left({ }^{\circ} \mathrm{C}\right)$ & $80-110$ \\
Air pressure $($ bar $)$ & 0.14 \\
\hline
\end{tabular}

Table 2. Parameters of the very-low-pressure plasma spray (VLPPS) and plasma spray-physical vapor deposition (PS-PVD).

\begin{tabular}{ccc}
\hline Parameters & VLPPS Coating & PS-PVD Coating \\
\hline Pressure $(\mathrm{Pa})$ & 150 & 150 \\
Current $(\mathrm{A})$ & 720 & 2600 \\
Torch & $\mathrm{F} 4-\mathrm{VB}$ & $\mathrm{O} C \mathrm{CP}$ \\
Power $(\mathrm{kW})$ & 53 & 126 \\
Plasma gas $(\mathrm{Ar})(\mathrm{SLPM})^{\mathrm{a}}$ & 60 & 90 \\
Plasma gas $(\mathrm{He})(\mathrm{SLPM})^{\mathrm{a}}$ & - & 30 \\
${\text { Plasma gas }\left(\mathrm{H}_{2}\right)(\mathrm{SLPM})^{\mathrm{a}}}^{\mathrm{a}}$ & 12 & - \\
Powder feed rate $\left(\mathrm{g} \cdot \mathrm{min}^{-1}\right)$ & 2 & 10 \\
Spraying distance $(\mathrm{mm}))$ & 250 & 800 \\
Substrate temperature $\left({ }^{\circ} \mathrm{C}\right)$ & $900-1000$ & $800-900$ \\
Torch speed $(\mathrm{mm} / \mathrm{s})^{\mathrm{S}}$ & 300 & 500 \\
\hline
\end{tabular}

a SLPM: standard liters per minute.

\section{Results and Discussion}

As shown in Figure 1a, the initial GDC powder had an irregular shape, and the particle size ranged from 100 to $350 \mathrm{~nm}$. After the agglomeration of the spray drying, the sphericity and surface uniformity of the GDC powder were improved (Figure 1b). Meanwhile, the particle size was increased with volume distributions $D_{10}, D_{50}$, and $D_{90}$ of $0.53,9.63$, and $22.2 \mu \mathrm{m}$, respectively (Figure $1 \mathrm{c}$ ). The relatively small micro-powder could be smoothly fed into the low-pressure plasma jet, and could also be quickly melted or vaporized to obtain a dense GDC coating.
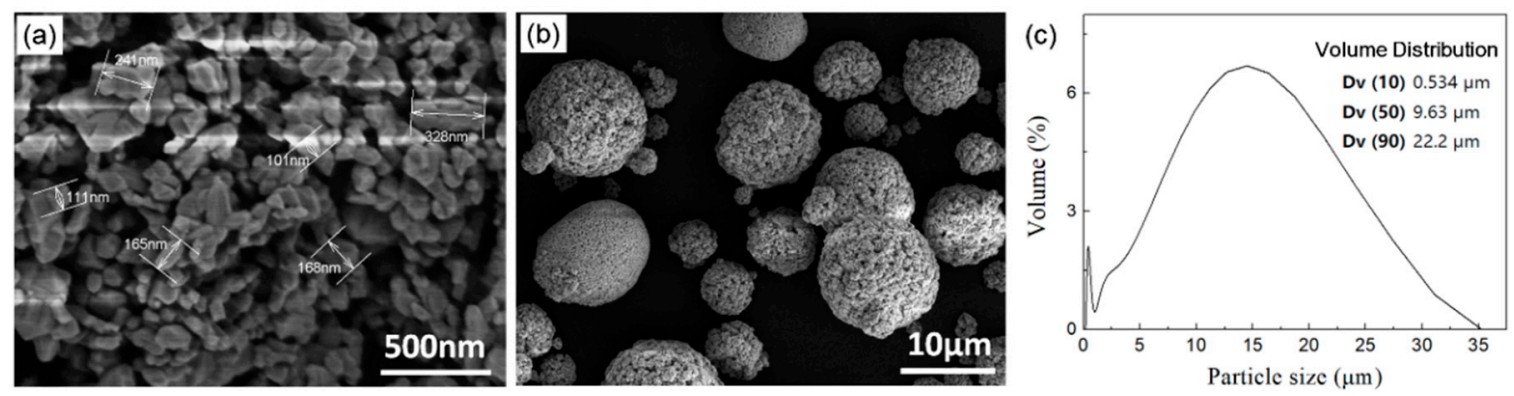

Figure 1. The SEM images of the (a) initial and (b) agglomerated GDC powder, (c) the particle size distribution of the agglomerated GDC powder. 
As shown in Figure 2a, by VLPPS consisted of splats and few unmelted particles. No vapor phase deposition was observed on the surface, indicating that it was a typical liquid deposition. The thickness of the VLPPS coating was about $60 \mu \mathrm{m}$ (Figure 2a'), and the microstructure was densely packed with a porosity of $4.28 \%$. No penetrating cracks or holes were noted in the coating, but there were fine pores in some places. The formation of pores and loose structures could be ascribed to the overlapping of the sprayed particles and the volume shrinkage caused by the droplet cooling. Figure $2 \mathrm{~b}$ presents a surface image of the GDC coating prepared by the PS-PVD process. As the PV-PVD used much higher plasma power and helium gas, the deposition state of the GDC powder began to change from the liquid phase to the vapor phase. Consequently, a mixed vapor and liquid deposition was formed, and the GDC coating was composed of cauliflower clusters and splats [14]. This mixed deposition-especially for the cauliflower clusters-would have a shadowing effect on the subsequent deposits. Hence, the PS-PVD coating had a higher surface roughness than the VLPPS coating. Fortunately, the mixed deposition obtained using the PS-PVD process eliminated the unmelted GDC powder that existed in the VLPPS process. Meanwhile, the resulting higher roughness did not create gaps between the adjacent cauliflower clusters. The cross-sectional image (Figure 2b') shows that the thickness of the PS-PVD coating was about $80 \mu \mathrm{m}$. The microstructure was composed of fine grains, columnar grains, splats, and small pores. The coating porosity was $2.57 \%$, which was denser than the VLPPS coating. No large gaps existed in the coating, and the columnar grains were surrounded by the fine grains and splats.
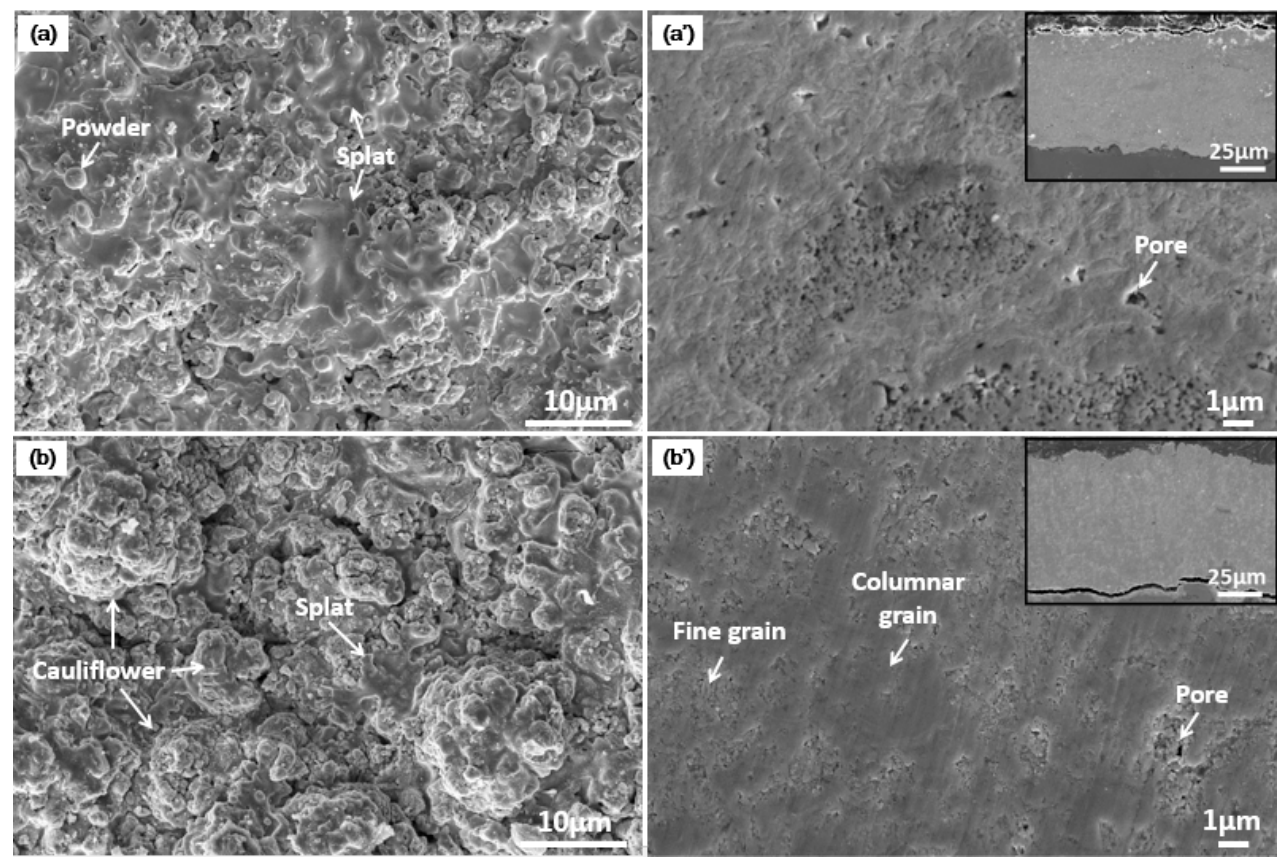

Figure 2. SEM images of GDC coatings: (a) surface of VLPPS coating; (a') cross section of VLPPS coating; (b) surface of PS-PVD coating; ( $\mathbf{b}^{\prime}$ ) cross section of PS-PVD coating.

In order to better explain the above phenomenon, the corresponding deposition mechanisms for the VLPPS and PS-PVD are summarized in Figure 3. On the one hand, the VLPPS coating had a typical lamellar structure with some pores between splats, which could decrease the density of the coating. However, when the powder was injected into the plasma jet, it underwent an accelerating and heating process. As the temperature of the plasma jet was higher than the melting temperature of GDC and the chamber pressure was very low, most of the powder could be fully melted and accelerated with very fast speed [15]. Once these melted particles landed on the substrate, a typical lamellar structure was built up. On the other hand, the PS-PVD coating had a mixed structure composed of the columnar grains, fine grains, and a few splats. The fine grains and splats filled the gaps between columnar 
grains, which led to a denser structure. Due to the high plasma power $(126 \mathrm{~kW})$ and the addition of helium gas, it was easy to obtain a mixed vapor and liquid deposition [14]. The columnar grains and fine grains were the results of vapor deposition. However, the nucleation mechanisms of the two are slightly different. Columnar grains are formed by heterogeneous nucleation on the substrate or the deposited coating, but fine grains are generated by homogeneous nucleation in the low-temperature parts of a plasma jet.

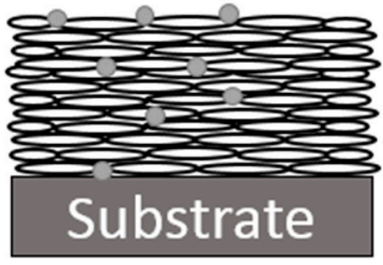

(a)

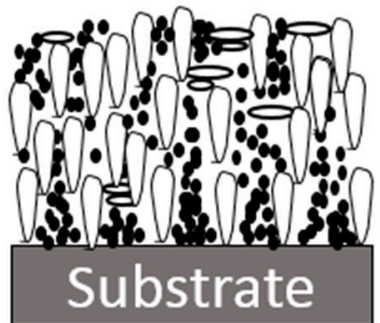

(b)

\section{- Unmelted particle \\ ○ Splat \\ Columnar grain \\ - Fine grain}

Figure 3. Schematic diagram of deposition mechanism for (a) VLPPS coating; (b) PS-PVD coating.

The XRD phase analyses of the initial GDC powder and coatings are shown in Figure 4. It can be found that the diffraction peak shape, position, and intensity ratio of the GDC coatings were consistent with the GDC powder, indicating that no phase transformation and preferred orientation formed in either sprayed coating. For further study, the grain sizes of the GDC powder and coatings were calculated based on the Scherrer equation [16]. The corresponding values of the initial GDC powder, VLPPS coating, and PS-PVD coating were 58.6, 29.6, and $30.5 \mathrm{~nm}$, respectively. After being melted/vaporized and recrystallized by VLPPS and PS-PVD, the grain sizes of both GDC coatings were significantly reduced. However, the peak intensity of the VLPPS coating was lower than that of PS-PVD coating, demonstrating that the VLPPS coating had a lower crystallinity. This can be attributed to the higher-temperature plasma jet of the PS-PVD, which promoted the crystallization of the GDC coating.

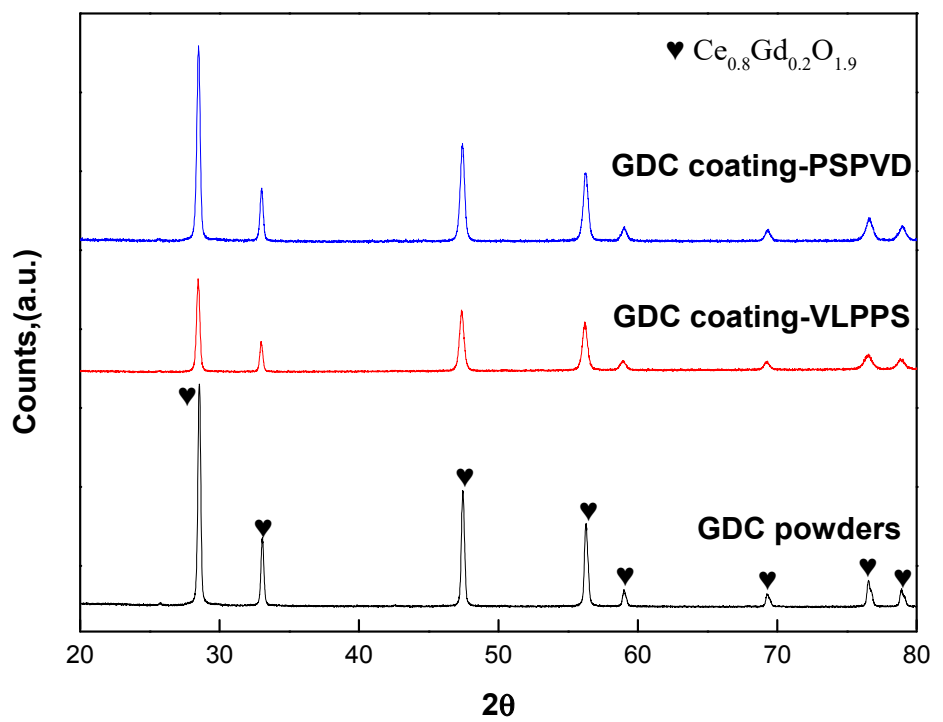

Figure 4. XRD patterns of the initial GDC powder and as-sprayed coatings.

Figure 5 reveals the mechanical properties of GDC coatings. The hardness and elastic modulus of the PS-PVD coating (9.3 and 163.4 GPa, respectively) were higher than those of the VLPPS coating (7.3 and $123.6 \mathrm{GPa}$, respectively), suggesting that the density and degree of crystallinity could influence the mechanical properties of coatings. Higher density and degree of crystallinity always benefit the 
hardness and elastic modulus, and as the PS-PVD coating had a lower porosity with a higher degree of crystallinity, its hardness and elastic modulus were higher than those of the VLPPS coating. Compared with another reference GDC coating [17], the microhardness of the VLPPS and PS-PVD coatings were close to the sintered sample. However, the elastic moduli of both sprayed coatings were lower than the sintered sample, because the density $(\geq 98 \%)$ and degree of crystallinity of the sintered sample were much higher.

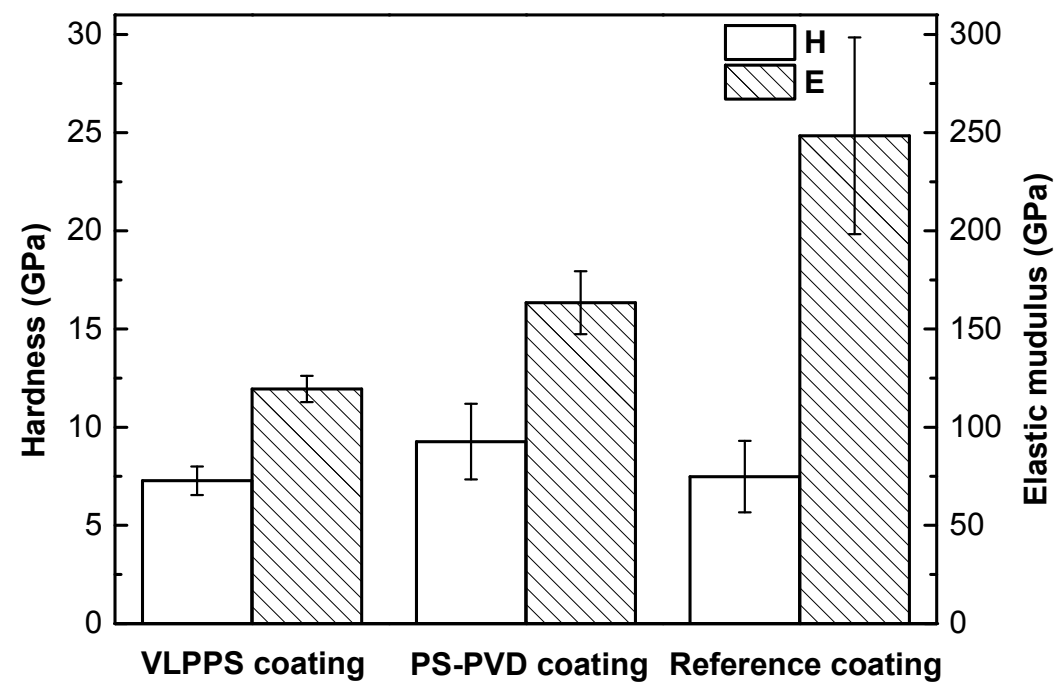

Figure 5. The mechanical properties of the as-sprayed GDC coatings and the reference GDC coating.

\section{Conclusions}

To summarize, an agglomerated GDC powder was prepared by spray drying, with an average particle size of $9.63 \mu \mathrm{m}$. Using the agglomerated powder, two GDC coatings were manufactured via VLPPS and PS-PVD. Although the morphologies of both coatings were dense, the deposition mechanisms of the two coatings were significantly different. The VLPPS coating was mainly formed by densely packed molten particles, while the PS-PVD coating was deposited by a mixed vapor phase and liquid splats. Moreover, the microhardness and elastic modulus of the PS-PVD coating were higher than those of the VLPPS coating, which could contribute to the higher density and better crystallinity. As the density and mechanical properties of the PS-PVD-prepared GDC coating were higher, it can be inferred that the PS-PVD coating is more appropriate for LT-SOFC application. To verify this, the electrical conductivities of the GDC coatings will be characterized in the following work.

Author Contributions: Conceptualization, J.W., C.S., and T.L.; methodology, J.W., C.S., S.N. and Z.D.; software, J.W., and C.S.; validation, J.W. and C.S.; formal analysis, J.W. and C.S.; investigation, J.W. and C.S.; resources, J.W. and C.S. and Z.D.; data curation, J.W. and C.S.; writing-original draft preparation, J.W.; writing-review and editing, J.W. and C.S.; visualization, J.W. and C.S.; supervision, M.L. and L.L.; project administration, Z.D., S.N., Y.Z. and L.L.; funding acquisition, M.L., C.S. and T.L.

Funding: This research was funded by the National Key Research and Development Program of China, grant number 2018YFB1502600, the Science and Technology Planning Project of Guangdong Province, grant number 2017B090916002, 2017A070701027, and 2014B070705007, and the Science and Technology Innovation Platform Project of Guangdong Academy of Sciences, grant number 2019GDASYL-0402004.

Conflicts of Interest: The authors declare no conflict of interest.

\section{References}

1. Singhal, S.C. Solid oxide fuel cells for stationary, mobile, and military applications. Solid State Ion. 2002, 152, 405-410. [CrossRef]

2. Brett, D.J.; Atkinson, A.; Brandon, N.P.; Skinner, S.J. Intermediate temperature solid oxide fuel cells. Chem. Soc. Rev. 2008, 37, 1568-1578. [CrossRef] [PubMed] 
3. Eguchi, K.; Setoguchi, T.; Inoue, T.; Arai, H. Electrical properties of ceria-based oxides and their application to solid oxide fuel cells. Solid State Ion. 1992, 52, 165-172. [CrossRef]

4. Sun, F.; Zhang, N.; Li, J.; Liao, H. Preparation of dense silicate electrolyte coating with low pressure plasma spraying and very low pressure plasma spraying for intermediate-temperature solid oxide fuel cells. J. Power Sources 2013, 223, 36-41. [CrossRef]

5. Gao, J.-T.; Wang, Y.-P.; Li, C.-X.; Zhang, S.-L.; Yang, G.-J.; Li, C.-J. Study on the Fabrication and Performance of Very Low Pressure Plasma Sprayed Porous Metal Supported Solid Oxide Fuel Cell. ECS Trans. 2017, 78, 2059-2067. [CrossRef]

6. Mauer, G.; Vaßen, R.; Stöver, D. Thin and Dense Ceramic Coatings by Plasma Spraying at Very Low Pressure. J. Therm. Spray Technol. 2010, 19, 495-501. [CrossRef]

7. Hui, R.; Wang, Z.; Kesler, O.; Rose, L.; Jankovic, J.; Yick, S.; Maric, R.; Ghosh, D. Thermal plasma spraying for SOFCs: Applications, potential advantages, and challenges. J. Power Sources 2007, 170, 308-323. [CrossRef]

8. Lang, M.; Henne, R.; Schaper, S.; Schiller, G. Development and characterization of vacuum plasma sprayed thin film solid oxide fuel cells. J. Therm. Spray Technol. 2001, 10, 618-625. [CrossRef]

9. Hospach, A.; Mauer, G.; Vaßen, R.; Stöver, D. Characteristics of ceramic coatings made by thin film low pressure plasma spraying (LPPS-TF). J. Therm. Spray Technol. 2012, 21, 435-440. [CrossRef]

10. Shin, T.H.; Shin, M.; Park, G.-W.; Lee, S.; Woo, S.-K.; Yu, J. Fabrication and characterization of oxide ion conducting films, $\mathrm{Zr} 1-\mathrm{x} \mathrm{M}$ x O $2-\delta(\mathrm{M}=\mathrm{Y}$, Sc) on porous SOFC anodes, prepared by electron beam physical vapor deposition. Sustain. Energy Fuels 2017, 1, 103-111. [CrossRef]

11. Marcano, D.; Mauer, G.; Vassen, R.; Weber, A. Manufacturing of high performance solid oxide fuel cells (SOFCs) with atmospheric plasma spraying (APS) and plasma spray-physical vapor deposition (PS-PVD). Surf. Coat. Technol. 2017, 318, 170-177. [CrossRef]

12. Virkar, A.V.; Nachlas, J.; Joshi, A.V.; Diamond, J. Internal precipitation of molecular oxygen and electromechanical failure of zirconia solid electrolytes. J. Am. Ceram. Soc. 1990, 73, 3382-3390. [CrossRef]

13. Oliver, W.C.; Pharr, G.M. An improved technique for determining hardness and elastic modulus using load and displacement sensing indentation experiments. J. Mater. Res. 1992, 7, 1564-1583. [CrossRef]

14. Mauer, G.; Hospach, A.; Vaßen, R. Process development and coating characteristics of plasma spray-PVD. Surf. Coat. Technol. 2013, 220, 219-224. [CrossRef]

15. Liu, S.-H.; Li, C.-X.; Zhang, H.-Y.; Zhang, S.-L.; Li, L.; Xu, P.; Yang, G.-J.; Li, C.-J. A novel structure of YSZ coatings by atmospheric laminar plasma spraying technology. Scr. Mater. 2018, 153, 73-76. [CrossRef]

16. Speakman, S.A. Estimating crystallite size using XRD. Available online: prism.mit.edu/XRAY/oldsite/ CrystalSizeAnalysis.pdf (accessed on 11 June 2019).

17. Korobko, R.; Chen, C.-T.; Kim, S.; Cohen, S.R.; Wachtel, E.; Yavo, N.; Lubomirsky, I.J.S.M. Influence of Gd content on the room temperature mechanical properties of Gd-doped ceria. Scr. Mater. 2012, 66, 155-158. [CrossRef]

(C) 2019 by the authors. Licensee MDPI, Basel, Switzerland. This article is an open access article distributed under the terms and conditions of the Creative Commons Attribution (CC BY) license (http://creativecommons.org/licenses/by/4.0/). 